\title{
Characterization of Pt nanoparticle decoration \\ of oxide layers on stainless steel
}

\author{
$\underline{\text { Stefan Ritter }}^{1}$, Pascal V. Grundler ${ }^{1}$, Robin Schaeublin ${ }^{2}$, Lyubomira Veleva ${ }^{1}$ \\ 1) Paul Scherrer Institute (PSI), Nuclear Energy and Safety Research Division, Laboratory for \\ Nuclear Materials, 5232 Villigen PSI, Switzerland, e-mail: stefan.ritter@psi.ch \\ ${ }^{2)}$ ETH Zurich, Scientific Center for Optical and Electron Microscopy (ScopeM) \& Laboratory for \\ Metal Physics and Technology, Department of Materials, 8093 Zurich, Switzerland
}

\begin{abstract}
Pt particles, injected into the feed water of boiling water reactors, are used to mitigate stress corrosion cracking in austenitic stainless steels of the primary water cooling circuit, but the mechanism behind this mitigation process is still not well understood. This feasibility study was performed, in order to get first insights and understanding on the deposition mechanism of the Pt particles, their shape and spatial distribution, with respect to stainless steel oxide crystals and their composition. The Pt particles and oxide crystals were characterized by electron microscopy, namely scanning electron microscopy, high-resolution transmission electron microscopy, and scanning transmission electron microscopy coupled to energy dispersive Xray spectrometry. It appears that the surface of the stainless steel is covered by polyhedral crystals, which consist of oxide of mainly $\mathrm{Fe}$, mixed with $\mathrm{Ni}$ and $\mathrm{Cr}$. $\mathrm{Fe}$ is rather homogeneously distributed within the crystals, while Ni concentrates in their centre relative to the $\mathrm{Cr}$ that segregates towards their surface. The Pt particles, with an average diameter of $14 \mathrm{~nm}$, stick to the oxide crystal's surfaces and are rather evenly distributed without preference to oxide composition. The particles are consisting of pure metallic Pt with a round to facetted or rhombohedral morphology.
\end{abstract}

Keywords: Platinum; nanoparticle; stainless steel, corrosion; oxide layer; boiling water reactor.

\section{Introduction}

Stress corrosion cracking (SCC) in reactor internals and metallic recirculation pipes is a wellknown corrosion issue in boiling water reactors (BWRs) [1, 2] and different methods have been used to mitigate it. In BWRs, the radiolysis of water with subsequent partitioning of the hydrogen into the steam is at the origin of highly oxidizing conditions which are a major cause of SCC [3]. Mitigation was attempted firstly by injecting $\mathrm{H}_{2}$ into the feed water, a method termed hydrogen water chemistry (HWC) [4]. Although $\mathrm{H}_{2}$ injection reduces the electrochemical corrosion potential and therefore lowers the SCC susceptibility, it has a problematic side-effect. The high $\mathrm{H}_{2}$ content favours the partitioning of reduced ${ }^{16} \mathrm{~N}$ species into the steam and thus significantly increases the steam line radiation dose rates.

A further development has been achieved by the addition of a catalyst that improves the recombination efficiency of the injected $\mathrm{H}_{2}$ with the reactive species $\mathrm{O}_{2}$ and $\mathrm{H}_{2} \mathrm{O}_{2}[5,6]$. Consequently the amount of $\mathrm{H}_{2}$ needed could be reduced, which in turn substantially decreased 
the amount of ${ }^{16} \mathrm{~N}$ in the steam. This catalytic technology, developed by General Electric to mitigate SCC, uses noble metals as catalysts, typically $\mathrm{Pt}$. $\mathrm{Na}_{2} \mathrm{Pt}(\mathrm{OH})_{6}$ solution is injected into

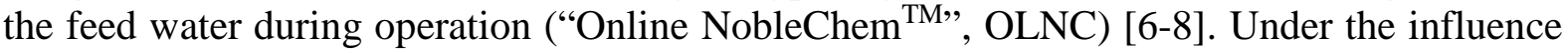
of the elevated temperature, the injected noble metal compounds decompose to a fine dispersion of nanometric metallic Pt particles, which may deposit on all water-wetted surfaces of the reactor system and stay there electrocatalytically active over extended periods, thus providing SCC mitigation if sufficient $\mathrm{H}_{2}$ is present [9]. For the efficiency of the OLNC technology, it is known that smaller Pt particles are advantageous with respect to SCC mitigation [6], under the assumption that the larger surface coverage provided by smaller particles for the same total amount of injected Pt is favourable to it. There is however still a lack of knowledge on the mechanisms by which these Pt particles incorporate onto the steel surface under nuclear power plant operative conditions.

The aim of this work is to gain first insights on the deposition mechanism of the Pt particles, their morphology and dispersion, with respect to oxide crystals and their chemical composition formed during the process, investigated using advanced electron microscopy.

\section{Experimental procedure and analytical techniques}

\subsection{Specimen OLNC treatment}

To produce specimens for electron microscopy investigations, stainless steel coupon specimens were exposed in a sophisticated high-temperature water loop and autoclave system (Figure 1). The loop reproduces the water chemistry of a BWR, but without irradiation. The water chemistry can be precisely adjusted in terms of $\mathrm{H}_{2}, \mathrm{O}_{2}$ and Pt content. The dissolved $\mathrm{H}_{2}$ and $\mathrm{O}_{2}$ concentrations, conductivity, electrochemical corrosion potential and fluid flow are closely monitored.

Coupon specimens $13 \times 10 \times 4 \mathrm{~mm}^{3}$ in size and made of AISI 304L stainless steel (Table 1), were pre-oxidized in the loop prior to the Pt application experiment. Pre-oxidation was performed for two weeks in a high-temperature water loop at $275^{\circ} \mathrm{C}$ with $170 \mathrm{ppb}$ dissolved $\mathrm{H}_{2}$ in highpurity water. For the experiment with Pt application, the pre-oxidized specimens were suspended in the water-filled autoclave under quasi-stagnant flow conditions (water velocity of a few $\mathrm{mm} \cdot \mathrm{s}^{-1}$ ). Concentrations for the dissolved gases $\mathrm{H}_{2}$ and $\mathrm{O}_{2}$ were $80 \mathrm{ppb}$ and $320 \mathrm{ppb}$, respectively, giving a molar ratio of $\mathrm{H}_{2}$ to $\mathrm{O}_{2}$ of about 4. The loop, loaded with the specimens, was pre-conditioned at $280{ }^{\circ} \mathrm{C}$ for 8 days under these BWR-HWC conditions prior to the start of the injection of $\mathrm{Pt}$ as a solution of $\mathrm{Na}_{2} \mathrm{Pt}(\mathrm{OH})_{6}\left(90 \mu \mathrm{g} \cdot \mathrm{kg}^{-1} \mathrm{Pt}\right)$. The Pt injection lasted for $450 \mathrm{~h}$ at a rate of $1.60 \mu \mathrm{g} \cdot \mathrm{h}^{-1}\left(0.3 \mathrm{~mL} \mathrm{~min}{ }^{-1} @ 90 \mu \mathrm{g} \cdot \mathrm{kg}^{-1} \mathrm{Pt}\right)$ into a water stream of $10 \mathrm{~kg} \cdot \mathrm{h}^{-1}$, resulting in a maximal Pt concentration in the loop water of $0.16 \mu \mathrm{g} \cdot \mathrm{kg}^{-1}$. The coupon specimens stayed in the loop for a total of $524 \mathrm{~h}$. More details about the experimental conditions can be found in $[10,11]$. 


\subsection{Analytical techniques}

Pt loading on the specimen surfaces was quantified by laser ablation - inductively coupled plasma - mass spectrometry (LA-ICP-MS). Calibration curves were established using in-house made stainless steel standards with known surface loadings of Pt, namely to 0.14 and $1.4 \mathrm{~nm}$ thick layer, corresponding to 0.3 and $3 \mu \mathrm{g} \cdot \mathrm{cm}^{-2}$ Pt surface loading, respectively.

The Pt treated stainless steel coupons were first studied by field emission gun scanning electron microscopy (SEM) at PSI on a ZEISS ULTRA 55 that has an ultimate resolution of $1 \mathrm{~nm}$. To better understand the bonding of the Pt particles to the oxide film, the spatial distribution and the morphology of Pt nanoparticles were further studied by transmission electron microscopy (TEM) and high-resolution TEM (HRTEM) as well as by scanning TEM (STEM) on a FEI Tecnai F30 operated at $300 \mathrm{kV}$ located at ScopeM ETH Zürich. Chemical imaging and analyses were done by high-angle annular dark field (HAADF) STEM and by scanning energy dispersive X-ray spectroscopy (EDS) on a FEI Tecnai Osiris, located at CIME EPFL Lausanne, as well as on a FEI Tecnai Talos located at ScopeM ETH Zürich. They consist both in a field emission gun TEM operated at $200 \mathrm{kV}$ and equipped with the X-FEG gun and the super EDS detector of FEI. Osiris achieves a spatial resolution in STEM imaging of $2.0 \AA$ while the more recent Talos achieves $1.6 \AA$, thank to, relative to the Osiris, the improved TEM column and new electronics. Its TEM column is based on the one of the upper class TEM, the TITAN. The $\mathrm{X}$-FEG combined to the super EDS detector allow a 60-times improvement in efficiency relative to a conventional EDS-equipped TEM, actually reducing the time to acquire a chemical map reasonable for such material from typically $1 \mathrm{~h}$ to 1 minute, while preserving the spatial resolution at about $1 \mathrm{~nm}$.

TEM/STEM specimens were prepared by using an extraction technique, allowing the removal of Pt particles together with some of the oxide crystals from the outer part of the oxide layer of the stainless steel. That way the Pt particles could be observed in the TEM/STEM in a state as close as possible to the one found on the actual steel surface. The extraction technique consists in the following (Figure 2): cellulose acetate dissolved in acetone was applied on the specimen surface; once the acetone has evaporated the cellulose acetate film was gently peeled off the specimen surface and carbon coated. The coated replicas were then cut with a razor blade to fit onto a standard $3 \mathrm{~mm}$ TEM Cu grid. Finally, drops of acetone were applied on the top of the replica to dissolve the cellulose acetate, leaving the oxide crystal with the Pt particles on the grid.

The Pt particle size distribution and average size was analysed based on the SEM micrographs using ImageJ software [12]. 


\section{Results and discussion}

\subsection{Pt surface loading and particle size distribution}

LA-ICP-MS chemical analysis shows that the average loading of Pt on the surface of the stainless steel coupons is $0.16 \mu \mathrm{g} \cdot \mathrm{cm}^{-2}$, which is in a range similar to the one observed on specimens taken from a BWR plant where OLNC technology is applied [13]. The specimens produced in the lab are therefore regarded as representative of nuclear power plant operative conditions.

Figure 3 shows a SEM image of the outer oxide layer covered with Pt particles, which are seemingly homogeneously distributed on its surface, with sizes in the nanometre range. The particle size distribution obtained by SEM shows that the Pt particles have a wide size range with a mean size of about $14 \mathrm{~nm}$ (Figure 4). One can also see in Figure 3 that the oxide surface presents edges and facets typical of crystalline oxides.

\subsection{STEM chemical map analysis}

In order to better understand the chemical composition of the oxide layer and, further, the preferential location of the Pt particles onto the oxide crystals, chemical mapping was performed using STEM. Figure 5 shows STEM chemical maps revealing the spatial distribution of $\mathrm{Ni}$ and $\mathrm{Cr}$ in the stainless steel oxide crystals, and the Pt in the nanoparticles. Note that the oxides contain also Fe, which is not shown here to get a clearer picture. Figure 5a reveals two types of oxides that are the following with the chosen elemental colour code. There are (1) the blue ones richer in $\mathrm{Cr}$ and (2) the green ones richer in $\mathrm{Ni}$ but with surfaces rich in Cr. Pt particles, marked in red, seem to preferentially attach to the surfaces of the oxide crystals, as seen in particular at higher magnification (Figure 5b). This was not so clearly visible in the SEM (Figure 3) due to the lower resolution. This is an important insight, because particles inside or below of the oxide crystals could not act as catalysts and therefore would not be able to contribute to SCC mitigation. The investigated oxide crystals have different faceted shapes and their sizes are in the range from 50 to $300 \mathrm{~nm}$. In Figure $5 \mathrm{~b}$ one can observe one type of oxide crystals with pyramidal shape in the range from 100 to $150 \mathrm{~nm}$. The EDS measurements show that the green oxides consist of $\mathrm{Fe}, \mathrm{Ni}$, and $\mathrm{Cr}$ oxide, with concentrations of $\mathrm{Ni}$ and $\mathrm{Cr}$ of respectively 12 and $2 \mathrm{wt}$ \% in the centre of the oxide, while in its edges they reach 18 and 12 wt.\%, respectively, the balance being Fe. These values correspond to an average made out of about 10 oxide crystals.

Figure 6 shows an integrated composition line profile across a green (Ni rich) oxide particle. The location of the line is depicted in the insert in Figure 5b. It confirms the strong enrichment in Cr towards the oxide surface, with an increase of up to six times relative to the centre of the oxide, together with a slight enrichment in $\mathrm{Ni}$, while Fe shows a decrease towards the surface.

Figure 5a exhibits also the second type of oxide crystals, the blue (Cr rich) oxides, which have smaller sizes, up to $100 \mathrm{~nm}$, and irregular but faceted shapes. EDS analyses show that these types of oxides contain $11 \mathrm{wt} . \% \mathrm{Cr}$ and $3 \mathrm{wt} . \% \mathrm{Ni}$. These values correspond to an average made over about 10 oxide crystals. It can be noticed that $\mathrm{Cr}$ and $\mathrm{Ni}$ segregate in the same way as in the former oxide type, with a gradient from the centre to the surfaces of the crystallites, but their concentration, along this gradient, is slightly changed relative to the former oxide type (green oxides).

The Pt particles can be observed on the larger oxides as well as on the smaller ones, without preferentially attaching to the $\mathrm{Ni}$ or $\mathrm{Cr}$ enriched surfaces of the oxides. Figure 7 presents a stereo pair of micrographs taken to locate the Pt particles with respect to the oxide's 
morphology. It confirms that they are located at the surface of the oxides. It should be stressed that this indicates that the Pt particles are not incorporated within the oxide particles, which would result in poor catalytic properties of the surfaces and therefore in an inefficient SCC mitigation.

The presence of two types of oxide crystals could be the results of the pre-oxidation of the specimens. The Ni rich were formed during the pre-oxidation phase. During the time in the loop where the Pt deposition took place, the Cr rich oxide particles formed and the Ni rich ones got their $\mathrm{Cr}$ rich outer layer. Therefore the chemical zoning of the oxide crystals provides a record of the different environmental conditions ( $\mathrm{H}_{2}$ only vs. $\mathrm{H}_{2}$ and $\mathrm{O}_{2}$ in $4: 1$ ratio) to which they were exposed during their growth.

\subsection{High-resolution TEM analysis of Pt particles}

The morphology of single Pt particles was studied by HRTEM imaging. The Pt particles have a crystalline structure and the regular pattern (Figure 8), as well as the high-resolution EDS analyses revealed that they consist of pure metallic Pt. A Fast Fourier Transform analysis provided a value for the lattice spacing of $0.227 \mathrm{~nm}$ (Figure 8). This value is very close to the d-spacing value of $\mathrm{Pt}(111)$ planes which is reported as $0.228 \mathrm{~nm}$ [14], therefore confirming once more that the particles consist of pure Pt.

The high-resolution investigations also have shown that the particles have different shapes depending on the size: round shape without or with facets mostly for sizes of about 2 to $20 \mathrm{~nm}$ (Figures 9a and 9b), or rhombohedral shape for sizes larger than about $20 \mathrm{~nm}$ (Figures 9c and 9d). Note that edges, steps, corners and twin boundaries are often sites of high catalytic activity [15]. Therefore, Pt particles rich in such features are likely to be more efficient catalysts, finally increasing the efficiency of the OLNC technology in mitigating SCC.

To summarize, it appears that the differences in the observed Pt particles including shape, size and orientation to the oxide matrix could indicate various mechanisms involved in the nucleation and growth of the Pt precipitates, as well as their binding to the oxides surface. Pt particles can be observed on the larger oxides, as well on the smaller ones, without preferential attachment relative to the $\mathrm{Ni}$ or $\mathrm{Cr}$ enriched areas of the oxides.

Finally it has to be emphasized that more of those very time-consuming high-resolution investigations of Pt particles are needed to confirm if the current observations are representative for all Pt-treated stainless steel surfaces and to be able to draw conclusions on the nucleation and deposition mechanisms of Pt nanoparticles. Such work is currently planned in a follow-up project. 


\section{Summary and conclusions}

Oxide crystals grown on stainless steel surfaces in high-temperature BWR water environment contain on average about 10-12 wt.\% Ni and 2-3 wt.\% Cr (and Fe for the balance). Mainly two types of oxides are observed, those that are richer in $\mathrm{Ni}$ with a strong $\mathrm{Cr}$ segregation towards the surface and those that are richer in Cr with little segregation. All oxide crystals are strongly facetted. Both types of oxides are rather evenly covered with Pt nanoparticles, without preferential attachment relative to the $\mathrm{Cr} / \mathrm{Ni}$ content on the surfaces. The investigated $\mathrm{Pt}$ particles are $14 \mathrm{~nm}$ in average size. They are crystalline and formed of pure metallic Pt. The smaller particles $(<20 \mathrm{~nm})$ present rather round to facetted shapes, while the larger ones show rhombohedral shapes. In conclusion, the current feasibility study has shown that such investigations are important for the validation of the OLNC as an efficient SCC mitigation technology.

\section{Acknowledgements}

The financial support of the research work ("NORA"-project) by the Swiss Federal Nuclear Safety Inspectorate (ENSI) and the contributions from the Swiss nuclear power plants Leibstadt (KKL) and Mühleberg (KKM) are gratefully acknowledged. Special thanks are expressed to Beat Baumgartner and Pia Reichel (both PSI) for the experimental support, as well as to CIME EPFL Lausanne for the technical support on the Osiris.

\section{References}

[1] R. Kilian, A. Roth, Materials and Corrosion, 53 (2002) 727-739.

[2] F. Cattant, D. Crusset, D. Féron, Mater. Today, 11 (2008) 32-37.

[3] C.J. Wood, Water chemistry control in LWRs, in: R.J.M. Konings (Ed.) Comprehensive Nuclear Materials, vol. 5, Elsevier, Oxford, 2012, 17-47.

[4] R.L. Cowan, C.C. Lin, W.J. Marble, C.P. Ruiz, Hydrogen water chemistry in BWRs, in: $5^{\text {th }}$ Int. Symposium on Environmental Degradation of Materials in Nuclear Power Systems Water Reactors, NACE, Monterey, CA, USA, 1991, 50-58.

[5] S. Hettiarachchi, R.L. Cowan, T.P. Diaz, R.J. Law, S.E. Garcia, Noble Metal Chemical Addition... from Development to Commercial Application, in: $7^{\text {th }}$ Int. Conference on Nuclear Engineering, JSME, Tokyo, Japan, 1999.

[6] P.V. Grundler, S. Ritter, PPChem., 16 (2014) 76-93.

[7] L. Oliver, B. Helmersson, G. Ledergerber, W. Kaufmann, G. Wikmark, B. Cheng, A. Kucuk, Review of Water Chemistry and Corrosion Products in a NWC Plant Transitioned to Hydrogen Injection and OLNC, in: Nuclear Plant Chemistry (NPC) Conference, CNS, Quebec, Canada, 2010. 
[8] S. Hettiarachchi, C. Weber, Water Chemistry Improvements in an Operating Boiling Water Reactor (BWR) and Associated Benefits, in: Nuclear Plant Chemistry (NPC) Conference, CNS, Quebec City, Canada, 2010.

[9] Y.-J. Kim, P.L. Andresen, S. Hettiarachchi, T.P. Diaz, Hydrothermal formation and distribution of noble metal particles on type 304 SS in high temperature water, in: CORROSION 2007, NACE, Nashville, TN, USA, 2007.

[10] P.V. Grundler, L. Veleva, A. Ramar, S. Ritter, Corrosion, 71 (2015) 101-113.

[11] P.V. Grundler, L. Veleva, A. Ramar, S. Ritter, A Comprehensive Investigation of the Platinum Application to BWRs to Mitigate Stress Corrosion Cracking, in: Nuclear Plant Chemistry (NPC) Conference, Atomic Energy Society of Japan, Sapporo, Japan, 2014.

[12] T.J. Collins, BioTechniques, 43 (2007) 25-30.

[13] S. Ritter, P.V. Grundler, G. Ledergerber, R. Pathania, Assessment of the platinum deposition behaviour on stainless steel surfaces in a boiling water reactor plant, Corrosion Engineering Science and Technology, accepted for publication (2017).

[14] K.-W. Park, J.-H. Choi, S.-A. Lee, C. Pak, H. Chang, Y.-E. Sung, J. Catal., 224 (2004) 236-242.

[15] S. Mostafa, F. Behafarid, J.R. Croy, L.K. Ono, L. Li, J.C. Yang, A.I. Frenkel, B.R. Cuenya, Journal of the American Chemical Society, 132 (2010) 15714-15719. 
Tables:

Table 1: Chemical composition of the AISI 304L (DIN no. 1.4306) stainless steel, in wt.\%.

\begin{tabular}{ccccccccccccc}
\hline $\mathbf{C}$ & $\mathbf{S i}$ & $\mathbf{M n}$ & $\mathbf{P}$ & $\mathbf{S}$ & $\mathbf{C r}$ & $\mathbf{M o}$ & $\mathbf{N i}$ & $\mathbf{C o}$ & $\mathbf{C u}$ & $\mathbf{N}$ & $\mathbf{N b}$ & $\mathbf{T i}$ \\
\hline 0.024 & 0.35 & 1.49 & 0.026 & 0.005 & 17.9 & 0.247 & 10.00 & 0.088 & 0.305 & 0.059 & 0.001 & 0.001 \\
\hline
\end{tabular}




\section{Figures:}

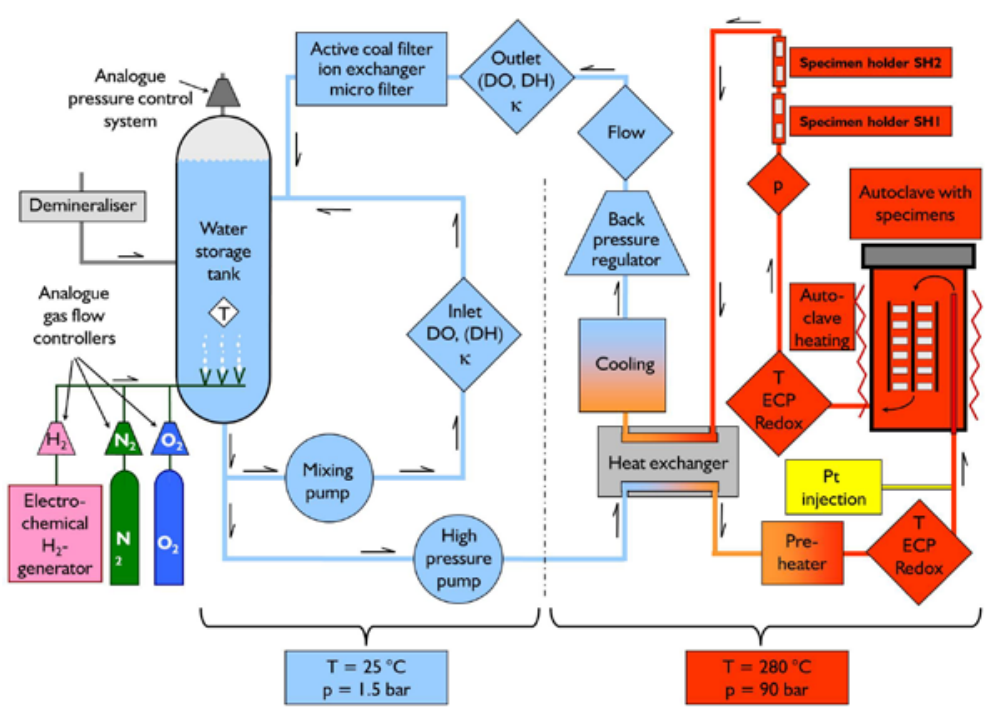

Figure 1: Schematic of the experimental setup (high-temperature water loop/autoclave) used to reproduce the water chemistry conditions of a BWR, but without irradiation.

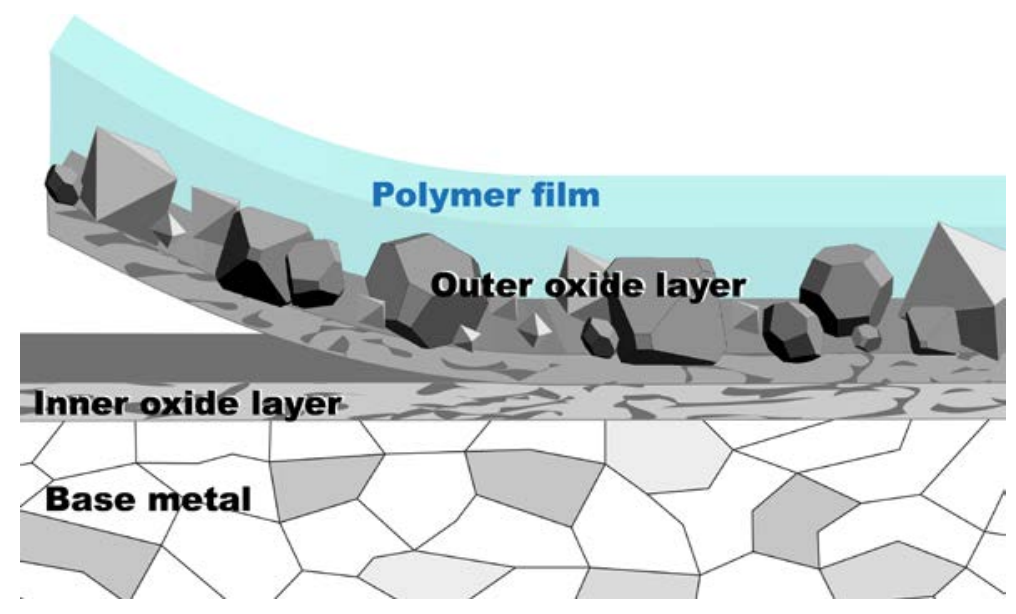

Figure 2: Schematics of the extraction preparation of the TEM/STEM specimens. 


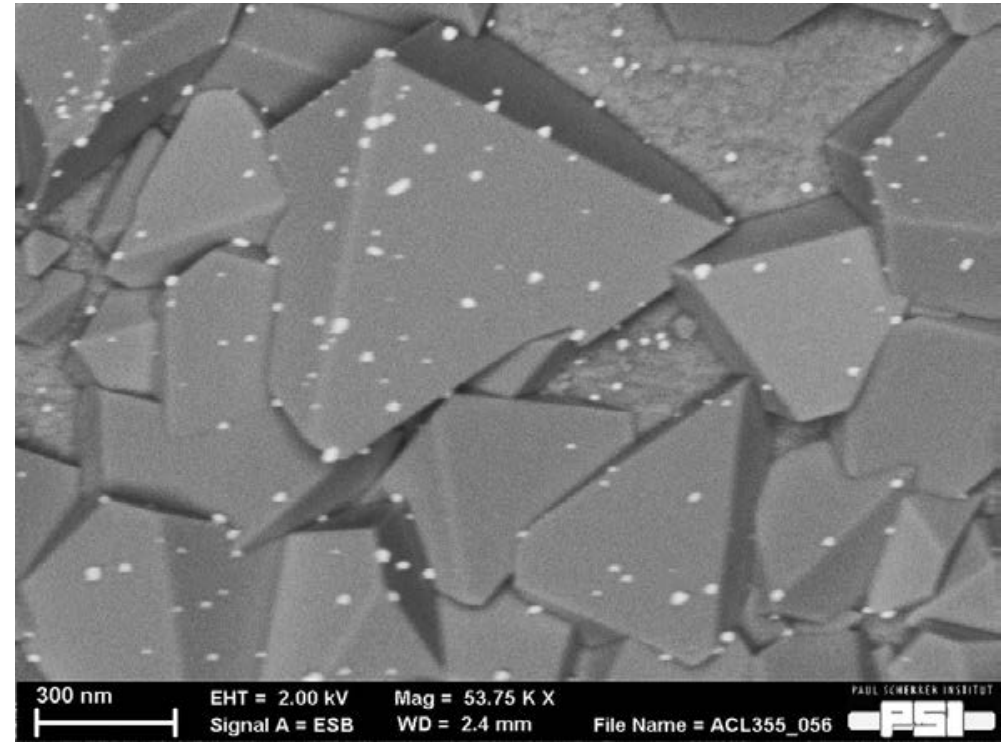

Figure 3: SEM micrograph obtained with backscattered electrons of AISI 304L stainless steel oxidized surface covered with Pt particles (bright spots) after exposure with Pt treatment in the high-temperature water loop at $280^{\circ} \mathrm{C}$ for $524 \mathrm{~h}$.

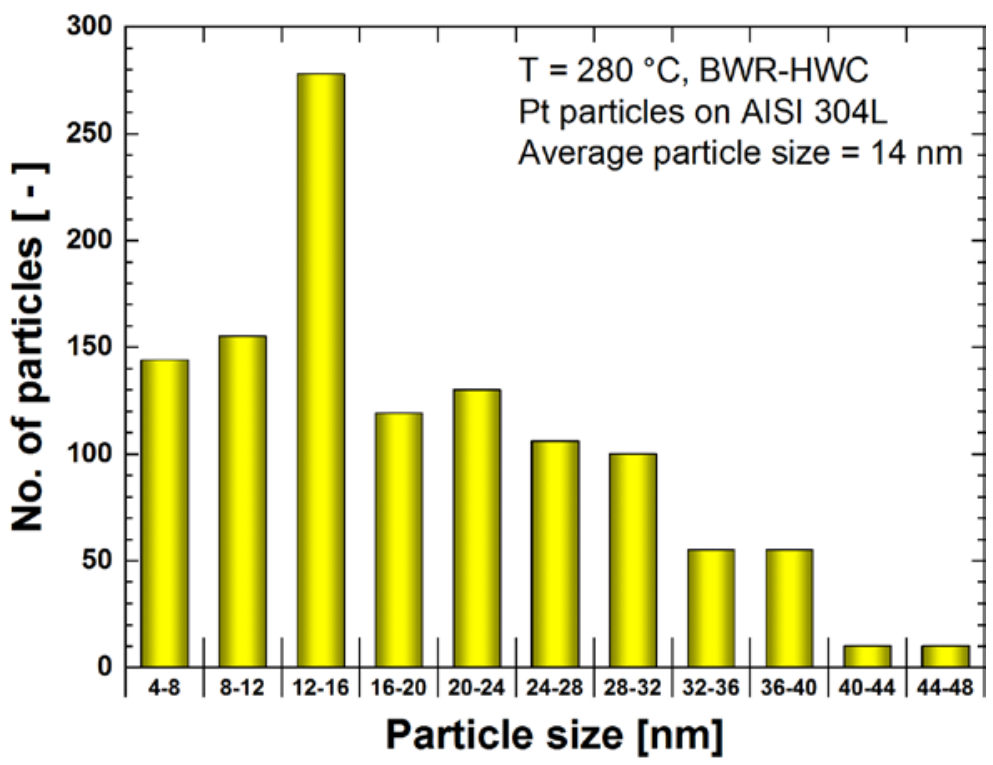

Figure 4: Size distribution of the Pt particles from the specimen shown in Figure 3 (analysed by ImageJ). 

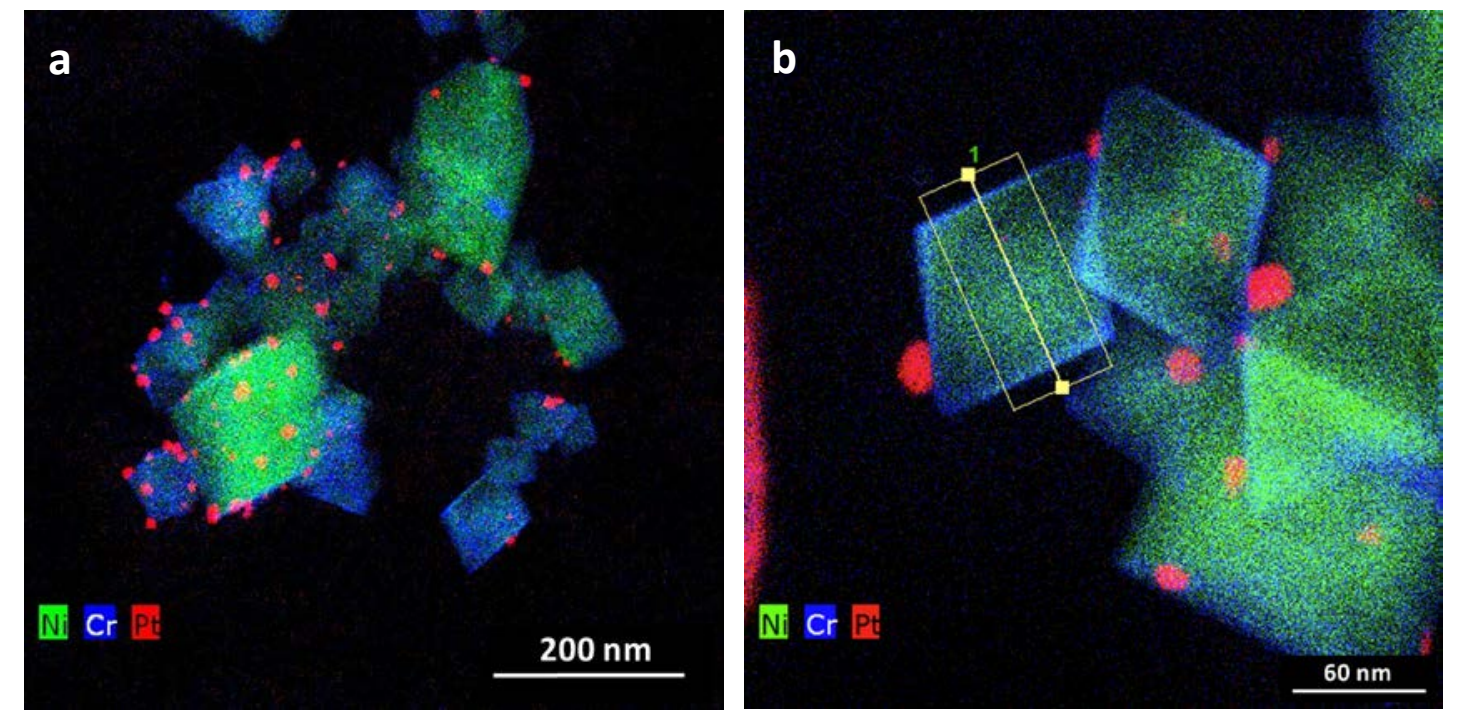

Figure 5: STEM chemical maps at two different magnifications as obtained by STEM EDS of the AISI 304L stainless steel oxide crystals decorated by Pt particles. Pt particles are attached only to the surfaces of the oxide crystals without preference of the oxide composition. Insert 1 in (b) indicates where the composition line profile presented in Figure 6 was made (details in the text).

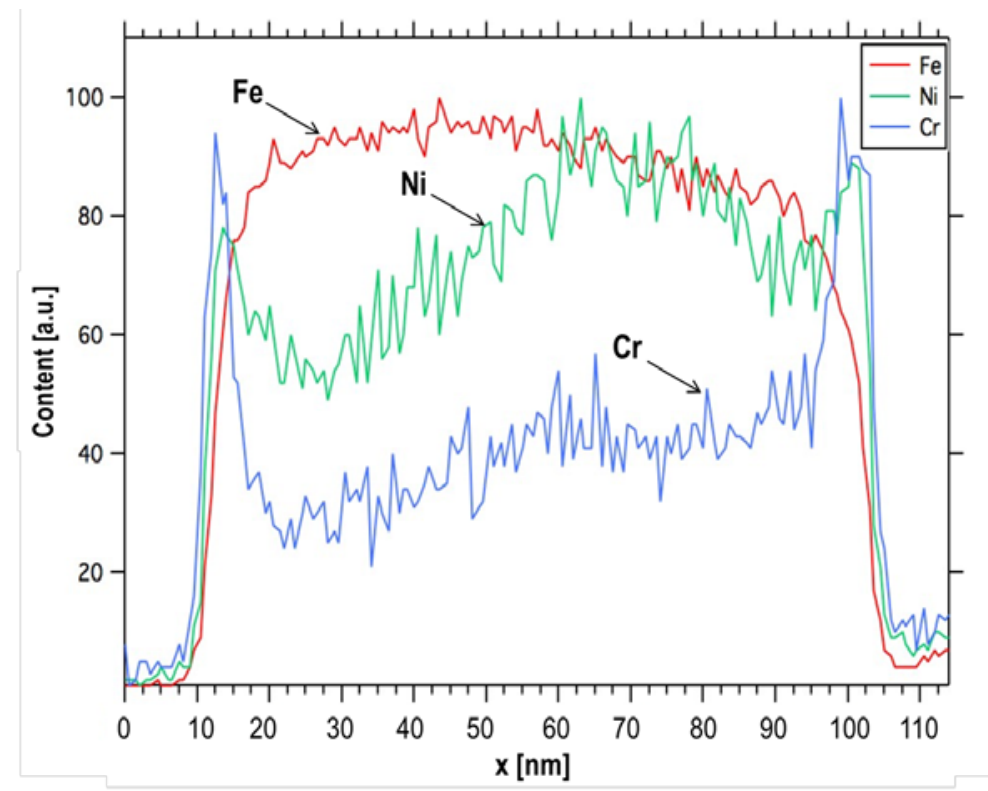

Figure 6: $\mathrm{Fe}, \mathrm{Cr}$ and Ni content across an oxide particle averaged over the line profile depicted in Figure 5b. 


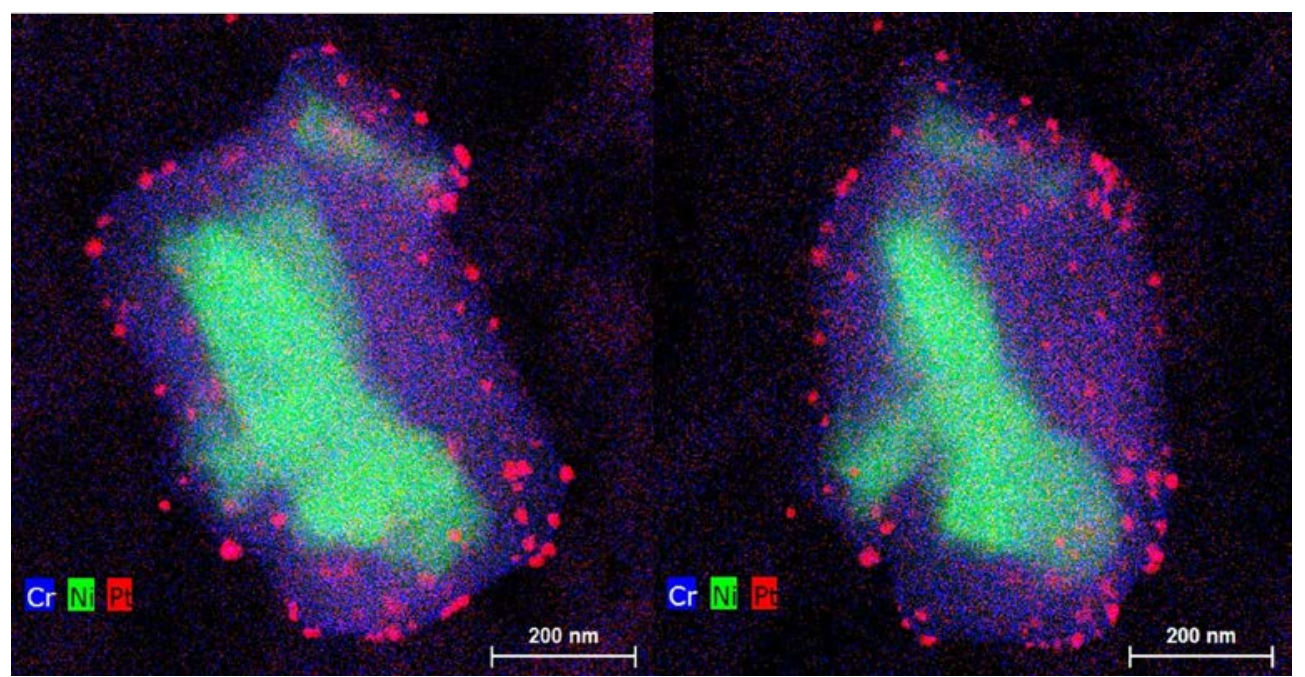

Figure 7: Stereo pair of chemical maps as obtained by STEM EDS of AISI 304L stainless steel oxide crystals decorated by Pt particles. There is $20^{\circ}$ between the two pictures.

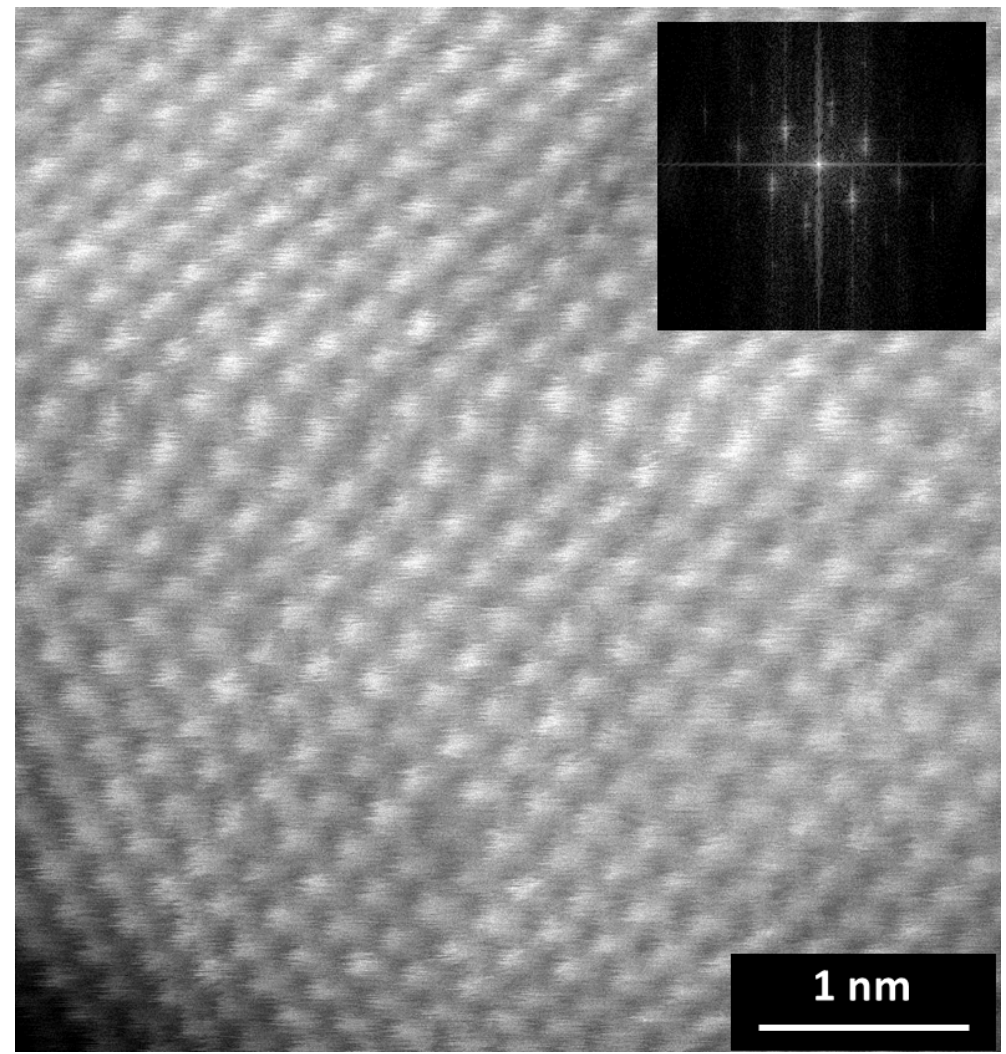

Figure 8: HRTEM dark field image of a Pt nanoparticle with corresponding Fast Fourier Transformation pattern (insert). 

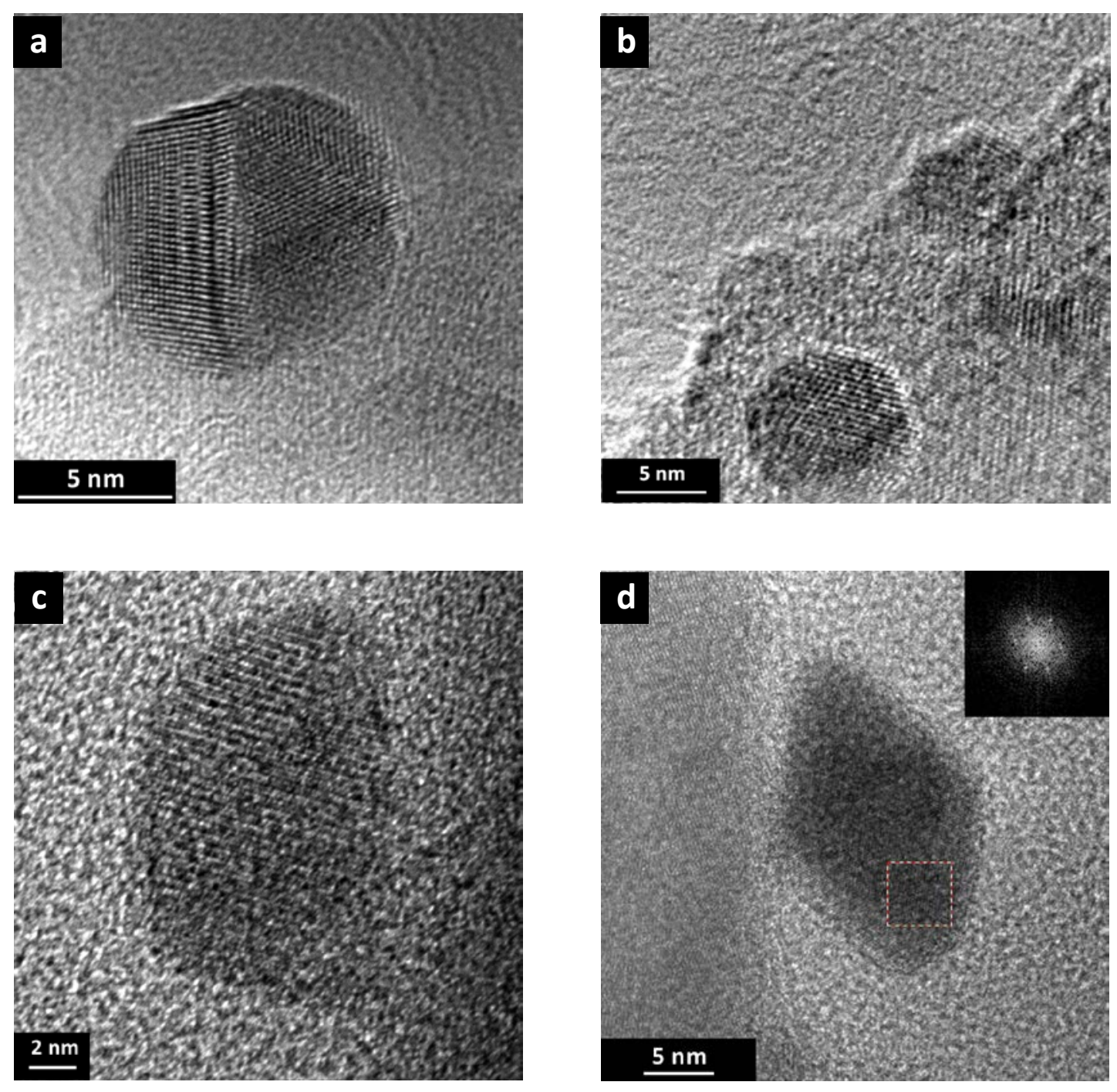

Figure 9: HRTEM bright field image of Pt nanoparticles attached to oxides (a, b, c), exhibiting different shapes. (d) Pt particle seen along the (111) direction of the oxide matrix. 